\title{
Recovery of Steelmaking Slag and Granite Waste in the Production of Rock Wool
}

\author{
Joner Oliveira Alves ${ }^{a *}$, Denise Crocce Romano Espinosa ${ }^{b}$, Jorge Alberto Soares Tenório ${ }^{b}$ \\ ${ }^{a}$ SENAI Innovation Institute of Mineral Technologies, Federation of Industries of the State of \\ Pará - FIEPA, Com. Brás de Aguiar Ave., 548, Nazaré, CEP 66035-405, Belém, PA, Brazil \\ ${ }^{b}$ Department of Metallurgical and Materials Engineering, Polytechnic School, University of \\ São Paulo - USP, Prof. Mello Moraes Ave., 2463, CEP 05508-030, São Paulo, SP, Brazil
}

Received: September 8, 2014; Revised: January 12, 2015

\begin{abstract}
Steelmaking slag and residues from granite cuttings are industrial wastes with considerable production, however limited applications. This work studied an inertization and recovery process of such wastes as raw materials into production of rock wool (i.e. a thermo-acoustic insulator with growing market). Several batches were produced aiming the chemical proprieties of a currently marketed rock wool. Mixtures were casted at temperatures of $1400-1500{ }^{\circ} \mathrm{C}$, then quenched in water and also poured into a Herty Viscosimeter. Produced materials with thickness smaller than $500 \mu \mathrm{m}$ were characterized by chemical analyses, XRD, SEM, EDS and DTA. ThermoCalc software was used to simulate the cooling curves of rock wools. Results showed that incorporation of wastes does not affect the main qualities of rock wool, the thermal insulation and prevention of fire spread. Raw material batches of rock wools may assimilate up to $66 \%$ of granite waste, or $53 \%$ steelmaking slag, or $70 \%$ combining both materials.
\end{abstract}

Keywords: steelmaking slag, granite waste, rock wool, thermal insulator

\section{Introduction}

Recycling of solid wastes has been growing steadily in recent years, along with rising industrial production. The waste generation increase presents a serious problem of environment and costly disposal. Recovery of industrial wastes into useful subproducts might be economically viable, and it is desirable since the disposal involves expensive transportation, as well as the monitoring of deposit areas ${ }^{1,2}$. Vitrification process has been widely used as final destination for hazardous materials due to the inertization capability of organic toxics, heavy metals, fly ashes and nuclear wastes ${ }^{3-5}$.

The world production of crude steel in 2010 reached about 1.4 billion tons, registering a new record of production. Considering that for each ton of steel produced are generated $150 \mathrm{~kg}$ of steelmaking slag, approximately 210 million tons of such waste were produced in $2010^{6,7}$. The production of steel from electric arc furnaces has expanded due to the higher availability of steel scrap, which is the main component of the production charge ${ }^{8}$. Steelmaking slag is the result of an aggregation of several elements which the presence is not important on steel making process. Among different wastes from the steel process, steelmaking slag represents one of most hazardous since it may contains heavy metals such as chromium, manganese and iron'. About $20 \%$ of the world's production of steelmaking slag is not reused due the characteristics of this waste, mainly the expansibility problem. A large portion of industrial parks are occupied for this waste, which raises the disposal costs. Therefore, recycling and reusing slag is a technical, economic and environmental solution for steel companies ${ }^{7,10}$.

*e-mail: joner.alves@cni.org.br
Another industrial sector with high production of waste is the industry of granite cutting. Approximately $30 \%$ of powdered wastes are generated during the granite extraction process, specifically on the rock cutting. Such values represents that a single company may produce up to 35 tons of this residue per month. The granite waste need be appropriately managed, since the discharge in rivers, lakes or watersheds can cause siltation. Also, this residue may cause serious human health problems, such as silicosis. Currently, the granite waste is mainly used in civil construction to produce materials in the form of mortar, bricks and tiles ${ }^{11,12}$. However, new applications for this waste are necessary due to the high produced volumes and the average growth of world production estimated at $6 \%$ per year ${ }^{13,14}$.

Rock wools are man-made mineral fibers (MMMF) fabricated with the melting of basalt or other natural rocks at temperatures above $1400{ }^{\circ} \mathrm{C}^{15,16}$. The thermo-acoustic characteristics of fire resistance, and not rendering toxic smoke ensure to rock wools a broad consumer market in the industries of construction, automotive, and electricelectronics, among others. Rock wools are usually produced with melting spinning process, in which a thin stream of material is dripped onto a wheel internally cooled with water or liquid nitrogen that causes a fast solidification ${ }^{17,18}$. This study aims to recovery steelmaking slag and granite cutting waste as feedstock of rock wools by the replacement of traditional raw materials, reducing the costs and impact of disposal of such residues. In addition, the use of recycled materials decreases extraction of non-renewable resources necessary to produce the rock wool. 


\section{Experimental Methods}

\subsection{Materials}

The raw materials used in this study were steelmaking slag from an Electric Arc Furnace (EAF), granite cutting residue from an industry on Espírito Santo State - Brazil, and chemical reagents (i.e. silica, alumina, magnesium oxide, iron oxide, calcium carbonate, and borax). Steelmaking slag was received in blocks, thus the material was cracked into pieces smaller than $4.76 \mathrm{~mm}$. Granite waste was received in a fine powder form, thus these were dried at $90{ }^{\circ} \mathrm{C}$ for 24 hours before use.

\subsection{Sample preparation}

Several mixtures were prepared using the residues and chemical additives. The batches were based on the chemical composition of a currently marketed rock wool provided by a thermo-acoustic company, and the range of composition recommended in the literature. Three cases were prepared: a) using only granite waste; b) using only steelmaking slag; and c) using both residues. The mixtures were homogenized during 10 minutes in a laboratory scale agitator.

The main objective of the work was maximize the amount of residues in the batches, however some tests presented melting points above the furnace capacity or insufficient fluidity to allow pouring, thus these materials were discarded from the investigation. In this aspect, the characterization work was performed in the materials from batches with efficient and superior incorporation of the residues. The mixing compositions of such batches were:

a) Using only granite waste - $66 \%$ granite waste and $34 \%$ chemical reagents $(22.7 \%$ calcium carbonate, $6.6 \%$ magnesium oxide and $4.7 \%$ iron oxide);

b) Using only steelmaking slag - 53\% steelmaking slag and $47 \%$ chemical reagents $(30.3 \%$ silica, $6.1 \%$ alumina, $6.1 \%$ magnesium oxide and $4.5 \%$ Borax);

c) Using both residues: $46 \%$ granite waste, $23 \%$ steelmaking slag and $31 \%$ chemical reagents $(21.9 \%$ calcium carbonate, $6.4 \%$ magnesium oxide and $2.7 \%$ iron oxide).

The batches were heated in a laboratory-scale electric furnace with no controlled gas atmosphere during $50 \mathrm{~min}$. The equipment operates open, the system pressure is constant, and a variation on oxygen pressure does not affect the equilibrium of phases. Melted samples were quenched in a water bath at room temperature in order to rapidly cool the materials, which is essential to produce vitreous materials. Three temperatures were used to cast the materials: 1400 , 1450 and $1500{ }^{\circ} \mathrm{C}$, such range was based on the method of rock wool production cited in the literature ${ }^{15,16}$. Temperatures of materials during the process were measured using an optical pyrometer. After the cooling process, samples of materials were collected and dried in an oven at $90{ }^{\circ} \mathrm{C}$ for 24 hours.

\subsection{Sample characterization}

Samples of produced materials in fiber forms and thickness smaller than $500 \mu \mathrm{m}$ were applied in the characterization processes. The nominal variation on the temperature not significantly affected the results of the produced materials, therefore only the characterization results of samples poured at $1450{ }^{\circ} \mathrm{C}$ were selected to present in this work.

Produced materials were characterized by chemical analysis, X-ray diffraction (XRD) and Differential Thermal Analysis (DTA). Scanning Electronic Microscopy (SEM) was used to verify formation of secondary phases in the produced materials, and Energy Dispersive Spectroscopy (EDS) was applied to establish the phase compositions. XRD analysis was carried out using a Philips MPD 1880 $40 \mathrm{~mA}$ Diffractometer adjusted with copper $\mathrm{K} \alpha$ radiation $(\lambda$ $=1.5418 \AA$ ) and voltage of $40 \mathrm{kV}$. The DTA was performed in a Netzsch 409C equipment with alumina crucibles, air atmosphere, and heating rate of $15^{\circ} \mathrm{C} / \mathrm{min}$. SEM/EDS analyses were conducted with a Philips XL-30 instrument using $3 \mathrm{kV}$ voltage and working distance of $8.2 \mathrm{~mm}$.

The Herty Viscosity Test is frequently used in industry to provide quick and approximate values for comparative purposes. A Herty viscometer is composed of two steel blocks with a groove in the middle interface in which the melted material is poured. Thus, the distance travelled by the material before solidification is measured, and an approximation of viscosity value is obtained ${ }^{19,20}$. A laboratory-scale Herty viscosimeter was applied in this work to measure variations on viscosity according to different batches compositions and casting temperatures.

ThermoCalc software version "n" running SLAG3 databases was used to perform thermodynamic and phase diagram calculations for multi-component systems of practical importance. In this work, the numerical code was used to simulate the cooling curves of an industrial rock wool and of the produced materials in order to compare the primary solid phases. Chemical compositions of the materials, previously determined, were used for the ThermoCalc simulations.

\section{Results and Discussion}

\subsection{Chemical analysis of wastes}

Results of the chemical analysis of steelmaking slag (see Table 1) shown that the main component of this residue is calcium oxide (46.9 wt. \%). The recovery of steelmaking slag has restricted applications due to the volume instability, in which the main cause is the phenomenon of hydration of free lime, although hydration of free magnesia may

Table 1. Chemical composition of residues used in the work (in wt. \%)

\begin{tabular}{ccc}
\hline Elements & Steelmaking slag & Granite waste \\
\hline $\mathrm{SiO}_{2}$ & 16.9 & 66.3 \\
$\mathrm{CaO}$ & 46.9 & 4.5 \\
$\mathrm{MgO}$ & 2.6 & 1.6 \\
$\mathrm{Al}_{2} \mathrm{O}_{3}$ & 5.4 & 19.3 \\
$\mathrm{Fe}_{2} \mathrm{O}_{3}$ & 16.2 & 2.3 \\
$\mathrm{MnO}$ & 5.5 & --- \\
$\mathrm{Cr}_{2} \mathrm{O}_{3}$ & 2.1 & --- \\
$\mathrm{Na}_{2} \mathrm{O}$ & --- & 1.3 \\
$\mathrm{~B}_{2} \mathrm{O}_{3}$ & --- & 0.8 \\
$\mathrm{Other}$ & 4.4 & 3.9 \\
\hline
\end{tabular}


also contribute ${ }^{7,21}$. The volume instability can be solved by submitting the steelmaking slag to a vitrification process ${ }^{22}$.

Table 1 also provides the chemical analysis of the waste from granite cuttings. The main components of this residue are silica and alumina, together such oxides are responsible for almost $86 \%$ of the chemical composition. Therefore, granite waste was used as a source of these components in the production of vitreous materials.

\subsection{Physical characteristics of formed materials}

Produced materials showed proprieties similar to glass: translucent, fragile and brittle at room temperature. The materials displayed a green color, which is reasonably due to the content of $\mathrm{Fe}_{2} \mathrm{O}_{3}$ (7.6-11.1\% by wt.). Different sizes and formats of materials were produced: pieces about $10 \mathrm{~mm}$, fibres with thickness about $500 \mu \mathrm{m}$, and thin powder.

\subsection{Chemical analysis of formed materials}

Table 2 provides the results of the chemical analyses of the rock wools produced in this study, sorted by each residue. This table also shows the chemical analyses of an industrial rock wool and the chemical composition range of rock wools cited in the literature ${ }^{16,23-25}$.

Produced materials showed high silica content (43.2-47.7\% by wt.), which is the most common glass forming oxide. Responsible for about $30 \%$ of the chemical composition of produced materials, $\mathrm{CaO}, \mathrm{MgO}, \mathrm{Na}_{2} \mathrm{O}, \mathrm{K}_{2} \mathrm{O}$ are usual glass modifiers that have the function of increase the fluidity and reduce the melting temperature. Alumina, $\mathrm{Fe}_{2} \mathrm{O}_{3}, \mathrm{MnO}_{2}$ and $\mathrm{TiO}_{2}$ are intermediary components that provide specific characteristics in rock wools, such as thermal resistance and chemical stability ${ }^{16,26}$.

A comparison of the values described in Table 2 shown that materials produced using only steelmaking slag or with both wastes are composed of similar major elements that industrial rock wool, and also in accordance with the chemical composition range of rock wools mentioned in the literature. Material produced only with the granite waste contains the major elements according to the reference values, with the exception of a small discrepancy in alumina content (14.2 wt. \%), which is difficult to control due to the high value found in the granite waste composition (19.3 wt. \%).

\subsection{Cooling curves of materials}

The cooling curve is an important factor on studies of vitreous materials since the cooling condition directly affects the structure of formed material. Simulation results using ThermoCalc software are shown in Figure 1, in which the curves express number of moles of a phase present in the system (NP) by the temperature.

Cooling curve based on the chemical composition of industrial rock wool is shown in Figure 1d. The first solid phase displayed is the spinel $\left(\mathrm{MgAl}_{2} \mathrm{O}_{4}\right)$ formed approximately at $1220^{\circ} \mathrm{C}$, and the second solid phase is the calcium silicate $\mathrm{CaO} \cdot \mathrm{SiO}_{2}$ formed around at $1210^{\circ} \mathrm{C}$.

Simulations using chemical compositions of the formed materials are shown in Figures 1a, 1b and 1c. The produced rock wools showed behaviour similar to the industrial rock wool, in which all samples presented spinel as the first phase and calcium silicate as the second phase. Spinel phases were formed at $1210-1290{ }^{\circ} \mathrm{C}$, and calcium silicate phases were formed at $1190-1220^{\circ} \mathrm{C}$.

Phase's diagrams of rock wools also showed the formation of the phases $\mathrm{CaO}-\mathrm{MgO}-\mathrm{SiO}_{2}, \mathrm{Fe}_{2} \mathrm{O}_{3}, \mathrm{MgO}-\mathrm{SiO}_{2}$ and $\mathrm{SiO}_{2}-\mathrm{Al}_{2} \mathrm{O}_{3}$ on a temperature range of $1140-1180{ }^{\circ} \mathrm{C}$. Such phases were not highlighted in Figure 1 in order to emphasise the temperatures of primary phases, which are directly related with the formation of vitreous materials.

ThermoCalc simulations also indicated that raw materials based on wastes (Figures 1a, 1b and 1c) and the traditional raw materials (Figure 1d) have approximate melting points, around $1200{ }^{\circ} \mathrm{C}$. Therefore, the use of steelmaking slag and granite waste as raw material should not affect the energy efficiency of the rock wool industrial process.

\subsection{X-ray diffraction analysis of materials}

The X-ray diffraction spectra of the produced materials are shown in Figure 2. Rock wool is an amorphous material, therefore it should present a homogeneous curve without notable crystalline peaks. The X-ray diffraction spectra of a current marketed rock wool is shown in Figure 2d, which

Table 2. Comparison of chemical compositions of rock wool samples: Industrial wool, literature range and produced materials sorted by each applied residue (in wt. \%).

\begin{tabular}{cccccc}
\hline \multirow{2}{*}{ Elements } & \multicolumn{2}{c}{ Reference Values } & \multicolumn{3}{c}{ Produced Materials } \\
\cline { 2 - 6 } & Industrial sample & Literature range & Granite waste $^{*}$ & Steel. slag & Both residues \\
\hline $\mathrm{SiO}_{2}$ & 44.9 & $41.0-53.0$ & 47.7 & 43.2 & 47.4 \\
$\mathrm{CaO}$ & 17.8 & $10.0-25.0$ & 17.6 & 22.6 & 19.6 \\
$\mathrm{Al}_{2} \mathrm{O}_{3}$ & 13.1 & $6.0-14.0$ & 14.2 & 10.6 & 11.5 \\
$\mathrm{MgO}$ & 8.5 & $6.0-16.0$ & 9.4 & 7.8 & 8.9 \\
$\mathrm{Fe}_{2} \mathrm{O}_{3}$ & 8.8 & $3.0-11.7$ & 7.6 & 11.1 & 7.6 \\
$\mathrm{Na}_{2} \mathrm{O}$ & 1.9 & $0.8-3.5$ & 1.9 & 2.2 & 2.4 \\
$\mathrm{~K}_{2} \mathrm{O}$ & 1.2 & $0.5-2.0$ & 1.0 & 0.2 & 1.1 \\
$\mathrm{MnO}$ & 0.3 & $0.0-0.3$ & 0.1 & 0.9 & 0.7 \\
$\mathrm{TiO}_{2}$ & 1.9 & $0.9-3.5$ & 0.4 & 0.1 & 0.3 \\
Others & 1.6 & $0.0-0.6$ & 0.1 & 1.3 & 0.5 \\
\hline
\end{tabular}

* Values cited in the literature by several authors: Buck $^{23}$; Liddell \& Miller ${ }^{24}$; Luoto et al. ${ }^{25}$; TIMA $^{16}$. 


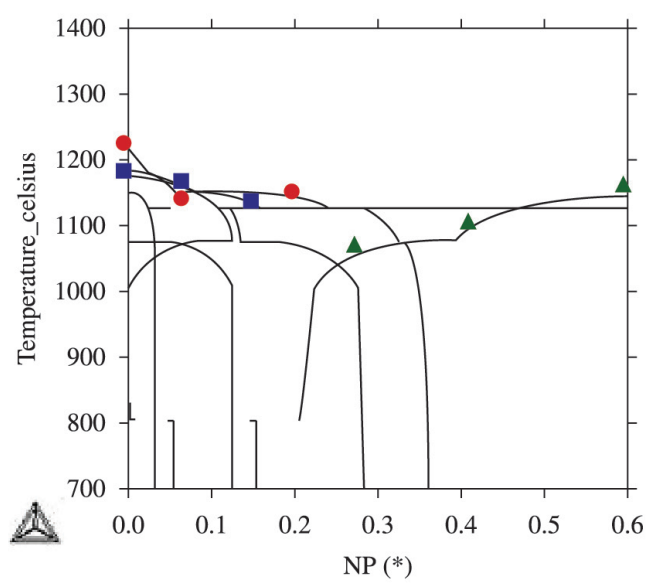

(a)

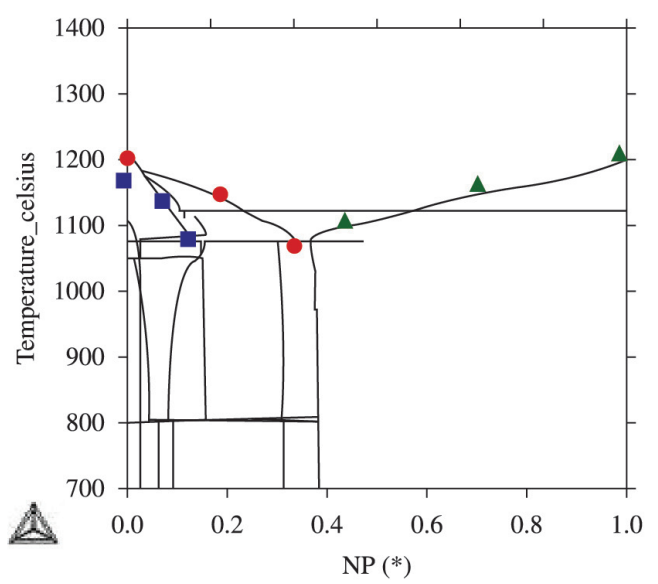

(c)

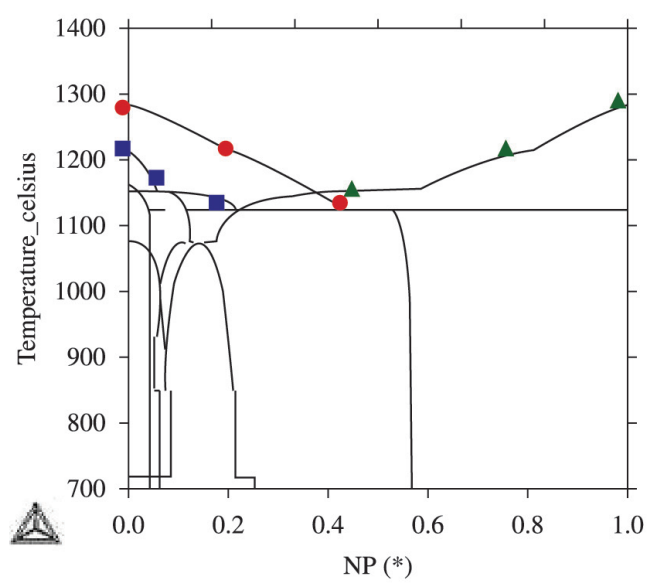

(b)

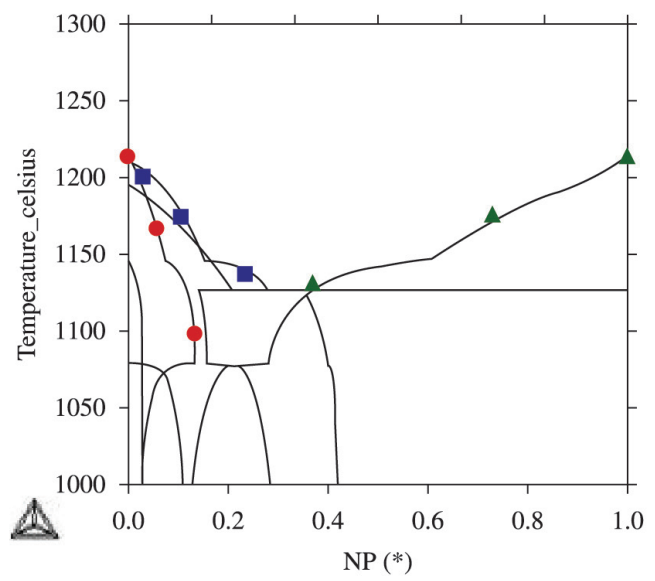

(d)

Legend: $\quad$ Spinel $\left(\mathrm{MgAl}_{2} \mathrm{O}_{4}\right) \quad$ Calcium silicate $\left(\mathrm{CaO} . \mathrm{SiO}_{2}\right) \quad \Delta$ Liquidus

Figure 1. Cooling curves of rock wools fabricated using only granite waste (a), only steelmaking slag (b), both residues (c), and from a industrial sample (d).

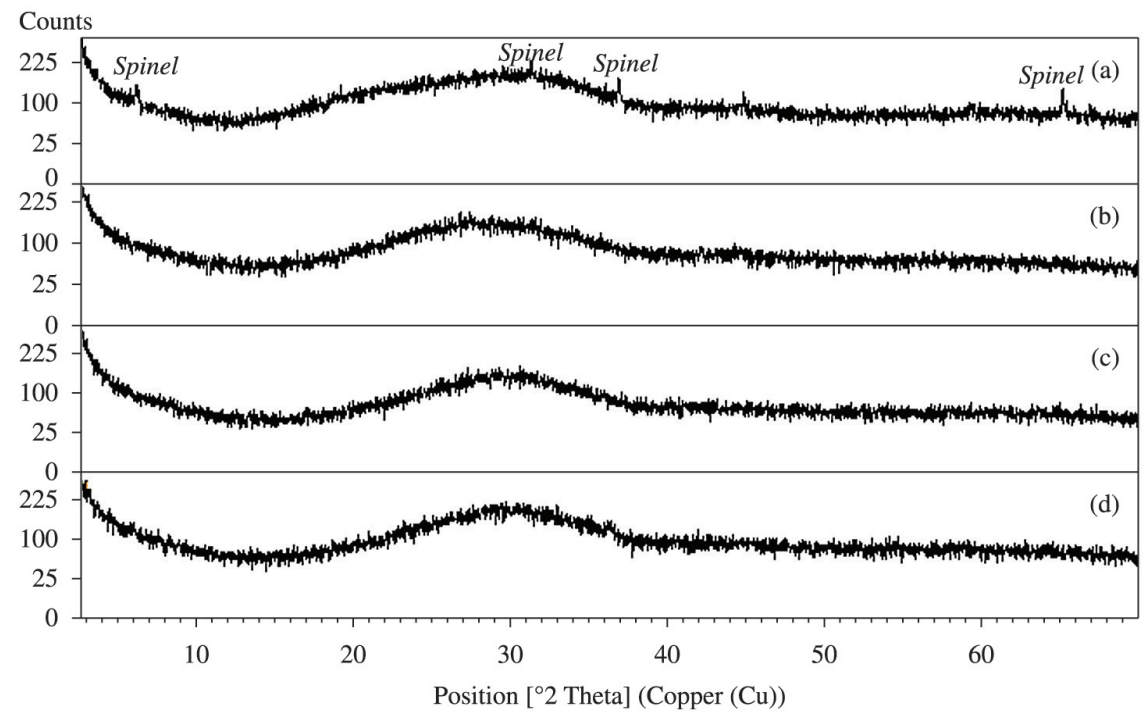

Figure 2. X-ray diffraction spectra of rock wools fabricated using only granite waste (a), only steelmaking slag (b), both residues (c), and from a industrial sample (d). 
confirms the homogeneous curve and serves as reference to compare with the produced materials.

The material obtained using only granite waste presented a spectrum with some crystalline peaks (see Figure 2a). Such peaks are characteristic of spinel, the first solid phase formed during the cooling, which is in accordance with the thermodynamic computational simulation of rock wools (Figure 1). The spinel formation indicates that the fast cooling process was not successfully performed, in other words, the process established enough time to form the first crystalline phase previously the occurrence of the vitrification.

Figures $2 \mathrm{~b}$ and $2 \mathrm{c}$ respectively shown the $\mathrm{X}$-ray diffraction spectra of materials produced using only steelmaking slag and both residues. Absence of notable crystalline peaks indicates that the materials are amorphous ${ }^{27}$. Therefore, the fast cooling processes were successfully performed.

\subsection{Scanning Electronic Microscopy (SEM) and Energy Dispersive Spectroscopy (EDS) analyses of materials}

Images obtained by SEM analysis of the formed materials are shown in Figure 3. The image of a current marketed rock wool is shown in Figure 3d. The homogeneous appearance of such image serves as reference to compare with the produced materials.

The image of rock wools produced using only granite waste is shown in Figure 3a, in which the formation of a secondary phase was presented. Thus, EDS analysis was used to identify this region, the obtained spectrum is shown on Figure 4. The result is characteristic of the spinel phase, such fact is consistent with the spinel peaks shown in the $\mathrm{XRD}$ image of this material (Figure 2a).

The homogeneous appearances shown in Figures $3 b$ and $3 \mathrm{c}$ indicate that secondary phases were not formed on materials produced using only steelmaking slag or both residues. Such results are in accordance with the amorphous curves in the XRD spectra obtained for these materials (Figures $2 \mathrm{~b}$ and $2 \mathrm{c}$ ).

\subsection{Differential Thermal Analysis (DTA)}

Figure 5 shows the results of DTA testing, where the graphics express the thermal behavior of the produced materials. Exothermic peaks correspond to the crystallization temperatures of the materials, while endothermic peaks represent the melting temperatures.

Differential thermal analysis of material produced using only granite waste is shown in Figure 5a. Results indicate a crystallization temperature of $780{ }^{\circ} \mathrm{C}$ and a

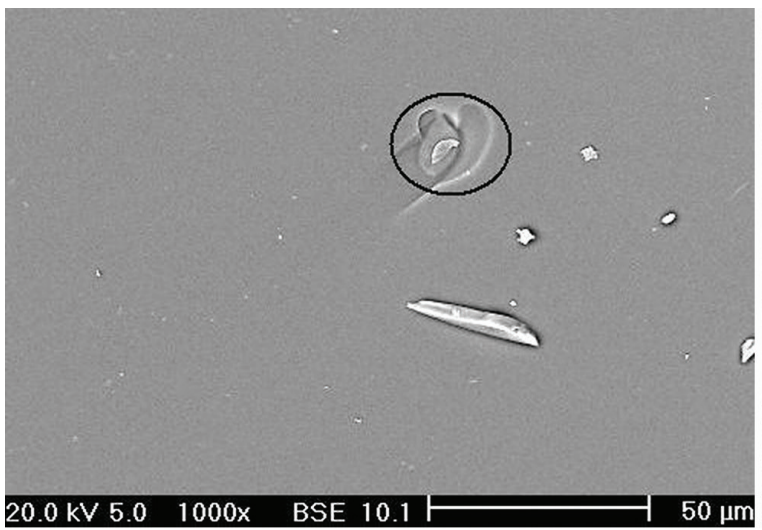

(a)

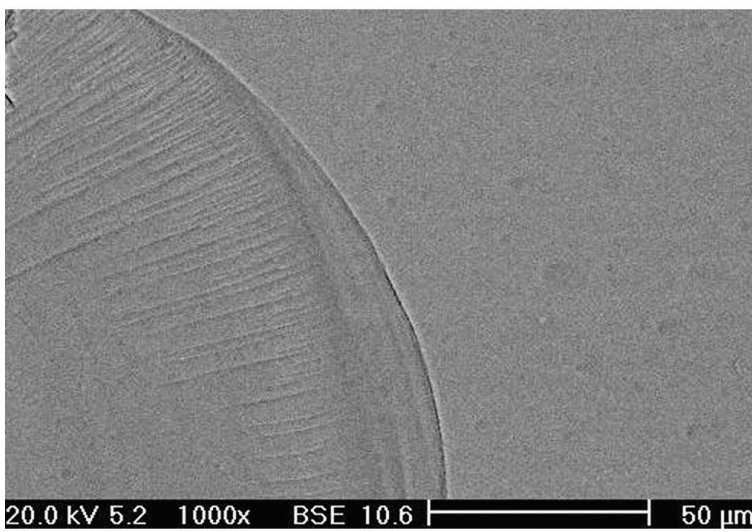

(c)

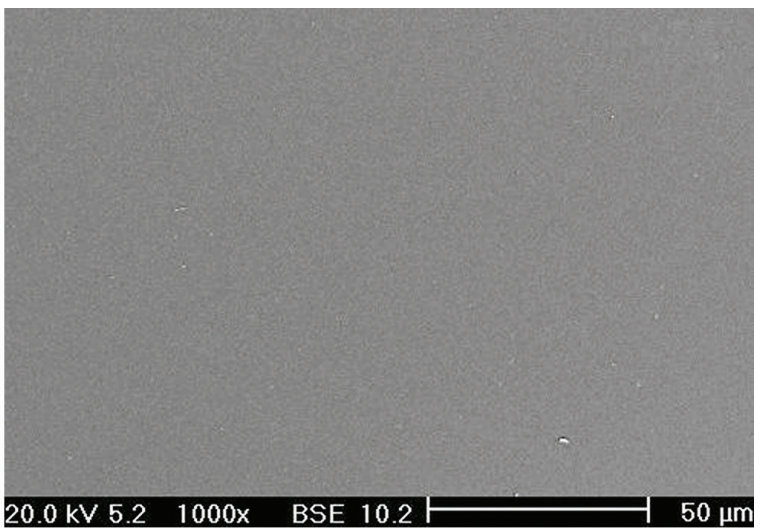

(b)

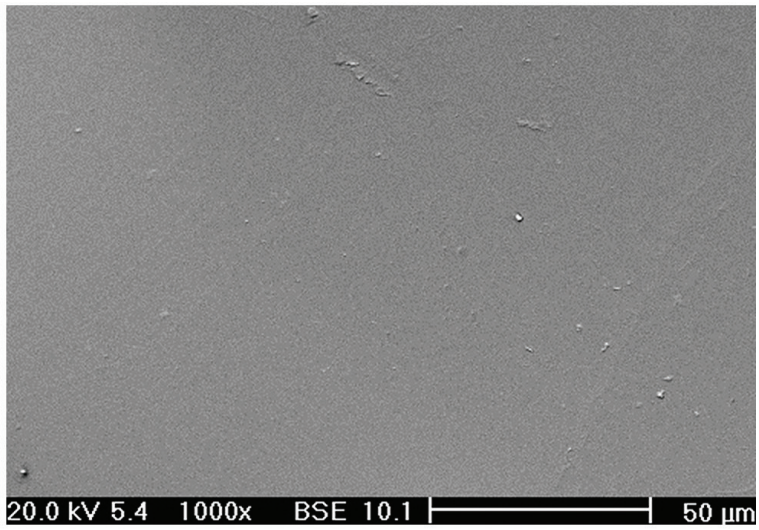

(d)

Figure 3. SEM images of rock wools fabricated using only granite waste (a), only steelmaking slag (b), both residues (c), and from a industrial sample (d). 


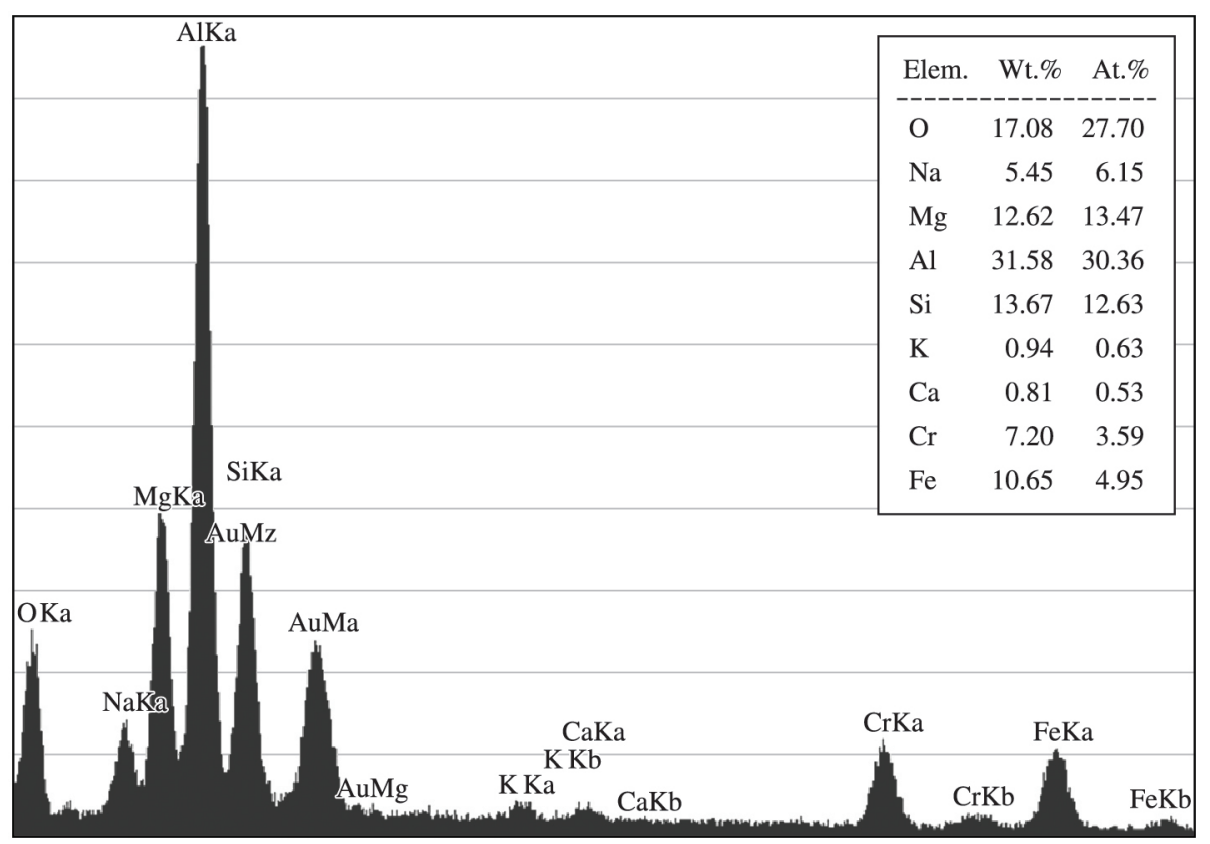

Figure 4. EDS of secondary phase found in the material produced using only granite waste.

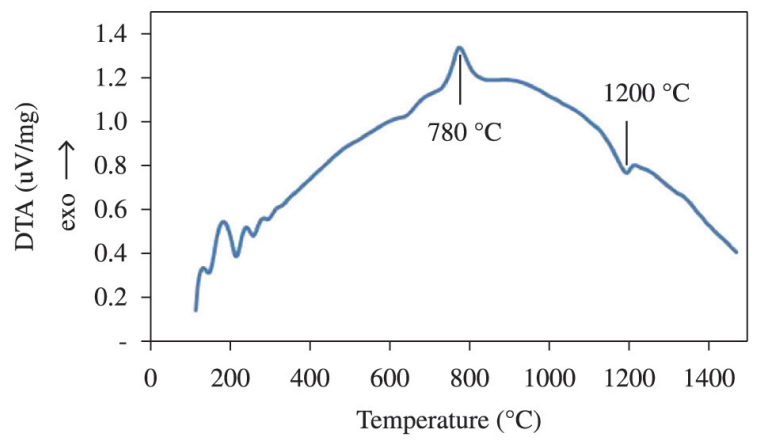

(a)

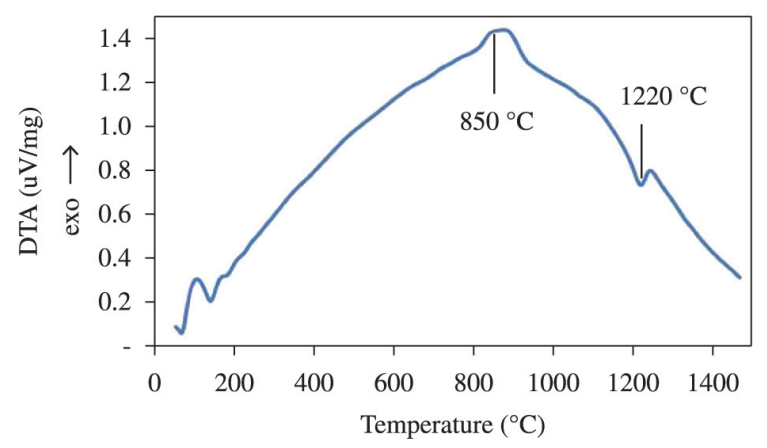

(c)

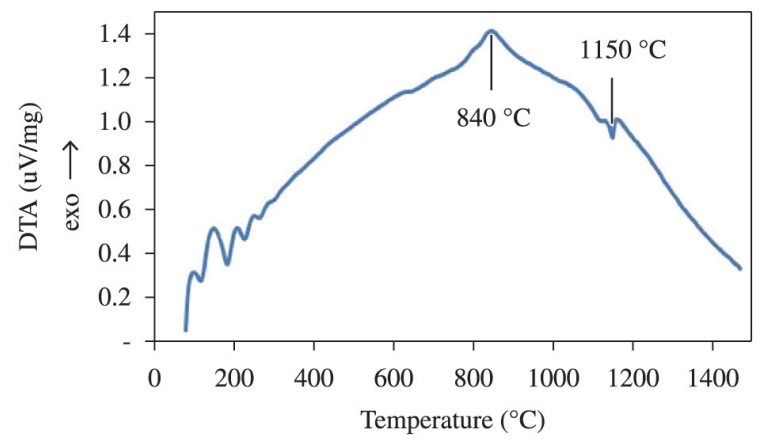

(b)

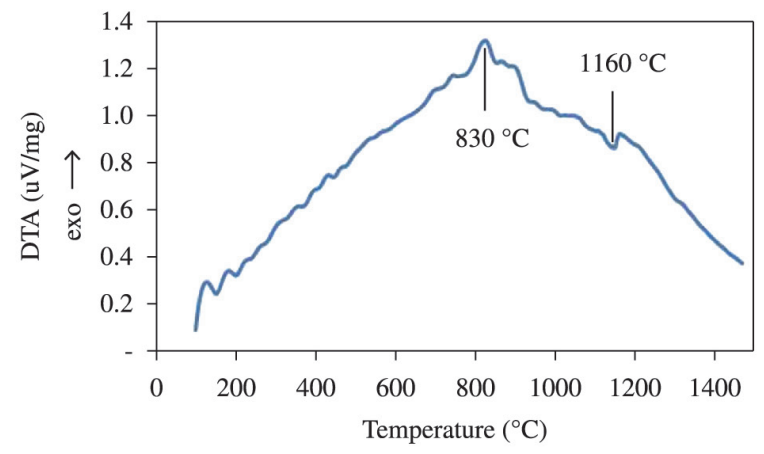

(d)

Figure 5. Differential thermal analysis of rock wools fabricated using only granite waste (a), only steelmaking slag (b), both residues (c), and from a industrial sample (d).

melting temperature of approximately $1200^{\circ} \mathrm{C}$. Figure $5 \mathrm{~b}$ shows that the material produced using only steelmaking slag presented a crystallization temperature of $840{ }^{\circ} \mathrm{C}$ and melting temperature of $1150{ }^{\circ} \mathrm{C}$. The association of both residues generated a material with crystallization temperature of $850^{\circ} \mathrm{C}$ and melting temperature of $1220^{\circ} \mathrm{C}$, as presented in Figure 5c. Images obtained by SEM analysis of the formed materials are shown in Figure 3. Results of all produced materials are in an accordance with the DTA obtained from a current marketed rock wool (Figure 5d), since the crystallization temperature of $830^{\circ} \mathrm{C}$ and melting temperature of $1160^{\circ} \mathrm{C}$ are close to the range obtained. 
Table 3. Herty Viscosity Tests: results of the distance traveled by each batch prior to solidify.

\begin{tabular}{cccc}
\hline $\begin{array}{c}\text { Casting } \\
\text { temperature }\end{array}$ & $\begin{array}{c}\text { Granite } \\
\text { waste }\end{array}$ & Steel. slag & Both residues \\
\hline $1400^{\circ} \mathrm{C}$ & $40 \mathrm{~mm}$ & $120 \mathrm{~mm}$ & $110 \mathrm{~mm}$ \\
$1450^{\circ} \mathrm{C}$ & $50 \mathrm{~mm}$ & $150 \mathrm{~mm}$ & $130 \mathrm{~mm}$ \\
$1500^{\circ} \mathrm{C}$ & $70 \mathrm{~mm}$ & $180 \mathrm{~mm}$ & $160 \mathrm{~mm}$ \\
\hline
\end{tabular}

Rock wool is employed for the manufacture of products designed to prevent fire spread. According to the Thermal Insulation Manufacturers' Association, the temperatures reached in a typical building fire are approximately $925^{\circ} \mathrm{C}$ and $1030{ }^{\circ} \mathrm{C}$ after 1 and 2 hours, respectively ${ }^{16}$. The rock wools present devitrification temperatures of about 725-900 ${ }^{\circ} \mathrm{C}$, then forming a polycrystalline material that is thermally and essentially dimensionally stable, which is high enough to contain a structural fire for several hours. The produced materials devitrified at temperatures of 780,840 and $850^{\circ} \mathrm{C}$, therefore these are within the recommended devitrification temperature range. Gualtieri et al. investigated several mineral wools and concluded that rock wool can be melted with a maximum firing temperature of $1100^{\circ} \mathrm{C} .{ }^{28}$ Produced materials in this work presented melting temperatures in the range of $1150-1220^{\circ} \mathrm{C}$, complying with the standard established for rock wools. Therefore, the above discussed thermal behavior of produced materials qualifies them as appropriate for use as fire inhibitors.

\subsection{Herty Viscosity Test}

Results of the Herty viscosity test are shown in Table 3. The measures indicate the distance traveled by the materials prior to solidify, therefore the highest fluidity values correspond to the lowest viscosities.

The batch produced using only granite waste presented the highest viscosities, while the material produced using only steelmaking slag showed lowest viscosities for all casting temperatures. Glass viscosity is directly affected by the function of oxides present in the chemical composition (glass former, glass modifier, or intermediary). Alumina does not forms a glass under normal conditions, however when added to an alkali-silicate glass it assumes a tetrahedral coordination similar to silica, i.e. becomes a glass former ${ }^{26,29}$. Considering the alumina as a glass former, the material produced using only granite waste contains $62 \%$ of glass forming elements and $30 \%$ of glass modifiers. Such proportions respectively change to 54\% / 33\% using only steelmaking slag, and to $59 \% / 32 \%$ using both residues. Differences on oxide contents capable of increase

\section{References}

1. Zhuo C, Alves JO, Tenório JAS and Levendis YA. Synthesis of carbon nanomaterials through up-cycling agricultural and municipal solid wastes. Industrial \& Engineering Chemistry Research. 2012; 51(7):2922-2930. http://dx.doi.org/10.1021/ ie $202711 \mathrm{~h}$

2. Alves JO, Zhuo C, Levendis YA and Tenório JAS. Microstructural Analysis of Carbon Nanomaterials Produced (glass formers) or decrease (glass modifiers) viscosity explains the discrepancy of fluidity found on produced materials ${ }^{27}$. Materials produced with only granite waste contains the highest proportion of glass forming elements $(62 \%)$ and presented the lowest fluidity range $(40-70 \mathrm{~mm})$. Furthermore, materials produced with only steelmaking slag contains the lowest proportion of glass forming (54\%) and presented the highest fluidity range (120-180 mm).

The viscosity decreased, i.e. fluidity increases, proportionally with growth of casting temperature for all the batches composition. Such phenomena is in accordance with the normal glass making behaviour, in which viscosity decreases logarithmically with the increase in temperature ${ }^{26,29}$. The increase on casting temperature from $1400{ }^{\circ} \mathrm{C}$ to $1500{ }^{\circ} \mathrm{C}$ resulted on fluidity alterations of $30 \mathrm{~mm}$ (only granite waste), $60 \mathrm{~mm}$ (only steelmaking slag) and $50 \mathrm{~mm}$ (both residues).

\section{Conclusions}

Tests performed using only granite waste showed that a maximum amount of $66 \%$ of this residue may be used in substitution to traditional raw materials during the manufacture of rock wool. The use of higher amounts of granite waste increases the viscosity, which causes difficulties in the quenching process. The high content of silica and alumina present in the granite waste establishes this material as a potential substituent for the glass formers in rock wool production. Steelmaking slag may assume up to $53 \%$ of raw materials in rock wool production, mainly substituting the calcium carbonate and iron oxide. Batches with only steelmaking slag presented the higher fluidity and lower melting temperature. The use of steelmaking slag combined with granite waste as raw materials for rock wool production proved to be efficient, and provides a substitution rate up to around $70 \%$ of the total mixture, with a 1:2 slag/granite waste weight ratio. Thermal analysis also showed that steelmaking slag and granite waste may be used as partial substitutes of raw materials in rock wool production, since the addition of such wastes does not affect the overall quality of the material produced in terms of thermal insulation and prevention of fire spread.

The recovery of steelmaking slag from EAF and residue from granite cuttings as raw materials in the production of rock wool is recommended due to the reduction in extraction of non-renewable resources necessary to produce such material. Furthermore, the technique may also contribute to reduce the costs and hazard of waste storage by steelmaking and granite extraction companies, since these are residues with considerable production and limited applications.

from Pyrolysis/Combustion of Styrene-Butadiene-Rubber (SBR). Materials Research. 2011; 14(4):499-504. http://dx.doi. org/10.1590/S1516-14392011005000078.

3. Chou I-C, Kuo Y-M, Lin C, Wang J-W, Wang C-T and Chang-Chien G-P. Electroplating sludge metal recovering with vitrification using mineral powder additive. Resources, Conservation and Recycling. 2012; 58:45-49. http://dx.doi. org/10.1016/j.resconrec.2011.10.006. 
4. Cimdins R, Rozenstrauha I, Berzina L, Bossert J and Bücker M. Glassceramics obtained from industrial waste. Resources, Conservation and Recycling. 2000; 29(4):285-290. http:// dx.doi.org/10.1016/S0921-3449(00)00053-7.

5. Quijorna N, Coz A, Andres A and Cheeseman C. Recycling of Waelz slag and waste foundry sand in red clay bricks. Resources, Conservation and Recycling. 2012; 65:1-10. http:// dx.doi.org/10.1016/j.resconrec.2012.05.004.

6. World Steel Association. Crude steel statistics. 2010. Available from: <http://www.worldsteel.org > . Access in: 25/05/2011.

7. Wang Q, Yan P and Feng J. A discussion on improving hydration activity of steel slag by altering its mineral compositions. Journal of Hazardous Materials. 2011; 186(2-3):10701075. http://dx.doi.org/10.1016/j.jhazmat.2010.11.109. PMid:21168967

8. Sebag MG, Korzenowski C, Bernardes AM and Vilela AC. Evaluation of environmental compatibility of EAFD using different leaching standards. Journal of Hazardous Materials. 2009; 166(2-3):670-675. http://dx.doi.org/10.1016/j. jhazmat.2008.11.125. PMid:19223119

9. Motz H and Geiseler J. Products of steel slags an opportunity to save natural resources. Waste Management. 2001;21(3):285293. http://dx.doi.org/10.1016/S0956-053X(00)00102-1. PMid:11280521

10. Pioro LS and Pioro IL. Reprocessing of metallurgical slag into materials for the building industry. Waste Management. 2004; 24(4):371-379. http://dx.doi.org/10.1016/S0956053X(03)00071-0. PMid:15081065

11. Moreira JMS, Freire MN and Holanda JNF. Utilization of granite sawing waste from Espírito Santo state in red ceramic. Cerâmica. 2004; 49(312):262-267.

12. Silva MA, Paes HR Jr and Holanda JNF. Reuse of ornamental rock-cutting waste in aluminous porcelain. Journal of Environmental Management. 2011; 92(3):936-940. http:// dx.doi.org/10.1016/j.jenvman.2010.10.060. PMid:21074931

13. Rodrigues GF, Alves JO, Tenório JAS and Espinosa DCR. Study of wastes from ornamental rocks for production of vitreous materials. Tecnologica em Metalurgia, Materiais e Mineração. 2011; 8(3):203-207. http://dx.doi.org/10.4322/ tmm.2011.032.

14. Menezes RR, Ferreira HS, Neves GA and Ferreira HC. The use of granite wastes as ceramic raw materials. Cerâmica. 2002; 48(306):92-101.

15. Trdič F, Sirok B, Bullen PR and Philpott DR. Monitoring mineral wool production using real-time machine vision. J. Real-Time Imaging. 1999; 5(2):125-140. http://dx.doi. org/10.1016/S1077-2014(99)80010-2.

16. Thermal Insulation Manufacturers' Association - TIMA. Manmade vitreous fibers: nomenclature, chemical and physical properties. Stamford: Owens-Corning Fiberglass; 1991. IPCS-WHO.

17. Ueda M, Murase F, Takahashi F and Matsumoto T. An optical system for measuring the eccentricity of glass wool pipe - for industrial use. Optics and Lasers in Engineering. 1999; 31(6):493-501. http://dx.doi.org/10.1016/S01438166(99)00030-5.

18. Marabini AM, Plescia P, Maccari D, Burragato F and Pelino $M$ New materials from industrial and mining wastes: glassceramics and glass- and rock-wool fibre. International Journal of Mineral Processing. 1998; 53(1-2):121-134. http://dx.doi. org/10.1016/S0301-7516(97)00062-8.

19. Brooks RF, Dinsdale AT and Quested PN. The measurement of viscosity of alloys -a review of methods, data and models. Measurement Science \& Technology. 2005; 16(2):354-362. http://dx.doi.org/10.1088/0957-0233/16/2/005.

20. Keene BJ. Slag atlas. 2nd ed. Düsseldorf: Verlag Stahleisen $\mathrm{GmbH} ; 1995$.

21. Wang G, Wang Y and Gao Z. Use of steel slag as a granular material: volume expansion prediction and usability criteria. Journal of Hazardous Materials. 2010; 184(1-3):555560. http://dx.doi.org/10.1016/j.jhazmat.2010.08.071. PMid:20843599

22. Juckes LM. The volume stability of modern steelmaking slags. Mineral Processing and Extractive Metallurgy. 2003; 112(3):177197. http://dx.doi.org/10.1179/037195503225003708.

23. Buck RL. Man-made vitreous fibers. Norfolk: U.S. Navy Environmental Health Center; 1997. Technical Manual NEHCTM6290.91-1, Rev. A.

24. Liddell D and Miller K. Mineral fibers and health. Boca Raton: CRC Publishers; 1991

25. Luoto K, Holopainen M, Kangas J, Kalliokoski P and Savolainen K. Dissolution of short and long rockwool and glasswool fibers by macrophages in flowthrough cell culture. Environmental Research. 1998; 78(1):25-37. http://dx.doi. org/10.1006/enrs.1997.3825. PMid:9630442

26. Bansal NP and Doremus RH. Handbook of glass properties. London: Academic Press; 1986.

27. Shi $\mathrm{C}$ and Zheng K. A review on the use of waste glasses in the production of cement and concrete. Resources, Conservation and Recycling. 2007; 52(2):234-247. http:// dx.doi.org/10.1016/j.resconrec.2007.01.013.

28. Gualtieri AF, Foresti E, Lesci IG, Roveri N, Gualtieri ML, Dondi M, et al. The thermal transformation of Man Made Vitreous Fibers (MMVF) and safe recycling as secondary raw materials (SRM). Journal of Hazardous Materials. 2009; 162(2-3):1494-1506. http://dx.doi.org/10.1016/j. jhazmat.2008.06.066. PMid:18675512

29. Harper CA. Handbook of ceramics, glasses, and diamonds. New York: McGraw-Hill Professional; 2001. 